\title{
Controlling Factors of the Particle Size of Spherical Silica Synthesized by Wet and Dry Processes
}

\author{
Keiji Saiki and Toshihiro Ishikawa
}

\begin{abstract}
We clarified the controlling factors of the particle size of the amorphous silica synthesized by wet and dry processes. In the wet process using methyl-trimethoxy-silane as a starting monomer, the obtained particle size can be easily controlled by changing the reaction time appropriately. However, to obtain larger particles, a relatively long time is needed. After the condensation reaction was conducted for $50 \mathrm{~h}$, the silica particles $\left(D_{50}: 3 \mu \mathrm{m}\right)$ were synthesized by calcination at $550^{\circ} \mathrm{C}$ in air. To synthesize larger silica particles, we used silicaseed particles $(8 \mu \mathrm{m})$ to obtain very large spherical silica particles $\left(D_{50}: 20 \mu \mathrm{m}\right)$. Thus, although the wet process needs a relatively long reaction time, it is very useful for synthesizing spherical silica particles with a wide range of particle size. In the dry process, we used methyl-trimethoxy-silane (MTMS), tetraethoxy-silane (TEOS), and octamethyl-cyclotetrasiloxane (OMCTSO) as the starting materials. In this process, the size of the silica particles was dominated by the molecular structure of the monomer, in particular, the number of silicon atoms contained in the monomer and the bulkiness of the substituent group. The largest silica particles were synthesized from OMCTSO, which contains the largest number of silicon atoms.
\end{abstract}

Keywords — Dry-process, Particle size, Spherical silica, Wetprocess.

\section{INTRODUCTION}

Amorphous silica particles have been widely used in many applications including paints, plastic compounds, and so on. The production processes of amorphous silica are classified into wet (alkoxide-derived silica, sodium silicate-derived silica) and dry (fumed silica) processes [1]-[5]. Of these processes, although the wet process can strictly control the particle-size with a regular morphology and a narrow size distribution, a relatively long manufacturing time is required; thus, the wet process is not suitable for industrial mass production. However, time-dependent propagation of the particle size makes it possible to produce larger silica particles. On the other hand, the dry process is a simple and instantaneous reaction that leads to better mass production, though control of the frame temperature and factory design are relatively difficult [6], [7]. In the dry process, many design factors have to be considered during factory construction: a steady frame temperature, oxygen content, the amount of raw material introduced, cooling conditions, and so on. Figure 1 shows the representative production processes of silica particles. As can be seen from this figure, the wet

Submitted on October 17, 2021.

Published on December 13, 2021

Keiji Saiki, Tokuyama Corporation, Japan.

(e-mail: f121701@ed.socu.ac.jp) process involves many reaction steps that use strong alkali or acid agents with washing and firing processes. In contrast, the dry process can produce high-purity, fine particles without further treatment such as drying and calcination. Consequently, the dry process is simpler than the wet process and is more suitable for industrial mass production.

In both processes (wet process and dry process), strict control of particle size and its distribution is very important. In this paper, we describe the important determining factors of the particle size of spherical silica particles synthesized by wet and dry processes.

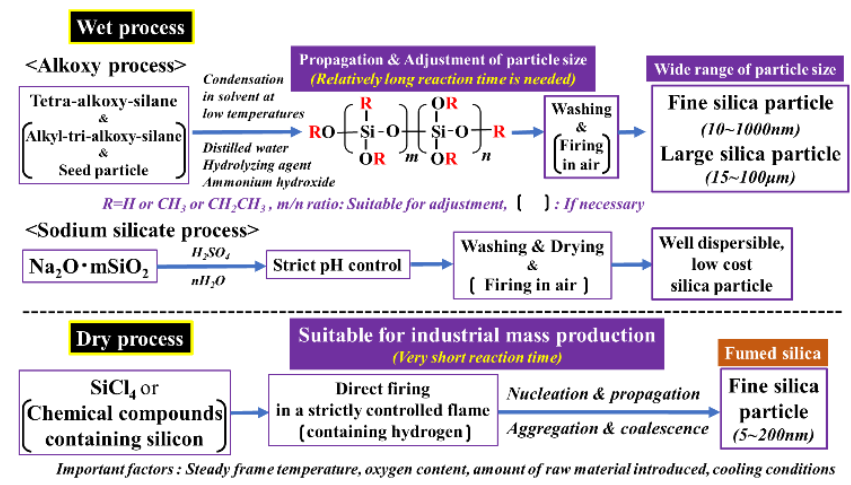

Fig. 1. Representative production processes of silica particles.

\section{EXPERIMENTAL PROCEDURE}

\section{A. Preparation of Silica Particles}

Silica particles were prepared via two types of processes (wet process and dry process). In the wet process, we adopted a sol-gel process using methyl-trimethoxy-silane as a starting material. Methyl-trimethoxy-silane $\left(\mathrm{CH}_{3} \mathrm{Si}\left[\mathrm{OCH}_{3}\right]_{3}, \mathrm{MTMS}\right.$, $99.999 \%)$, ethanol $\left(\mathrm{C}_{2} \mathrm{H}_{5} \mathrm{OH}, 99 \%\right)$, and ammonium hydroxide solution $\left(\mathrm{NH}_{4} \mathrm{OH}, 28 \%\right)$ were purchased from Fujifilm Wako Pure Chemical Corporation. All reagents were used as received without further purification. The temperature of the reaction solution was kept in the $0-5{ }^{\circ} \mathrm{C}$ temperature range. We used a reaction mixture containing MTMS as the precursor, ethanol as the solvent, distilled water as the hydrolyzing agent, and ammonium hydroxide as the catalyst for the hydrolysis and condensation of the alkoxide. First, a solution- 1 containing $1.8 \mathrm{ml}$ of MTMS and $20 \mathrm{ml}$ of ethanol was magnetically stirred and cooled by using a handmade heat exchanger. A solution-2 containing $5.5 \mathrm{ml}$ of ammonium hydroxide in $8 \mathrm{ml}$ of distilled water was cooled to

Toshihiro Ishikawa, Tokyo University of Science, Yamaguchi (SanyoOnoda City Universiry), Japan.

(e-mail: ishikawa@@rs.socu.ac.jp) 
the same temperature as the previous solution-1. The synthesis reaction was performed by dropping the solution-2 into the solution-1 slowly. After the synthesis, the obtained precursor-polymer particle was separated from the mixed solution, and carefully washed with distilled water. The cleaned precursor-polymer was calcinated in air at $550^{\circ} \mathrm{C}$ for $1 \mathrm{~h}$ to obtain the silica particles. To prepare larger silica particles, we added silica seed particles of $8 \mu \mathrm{m}$ into the solution-1 without changing the other aspect of the synthesis process. This process was performed using a previous information as a reference [8].

In the dry process, methyl-trimethoxy-silane $\left(\mathrm{CH}_{3} \mathrm{Si}\left[\mathrm{OCH}_{3}\right]_{3}, \mathrm{MTMS}\right.$, molar mass: $136 \mathrm{~g} / \mathrm{mol}$, boiling point: $102^{\circ} \mathrm{C}$, FUJIFILM Wako Pure Chemical Corporation), tetra-ethoxy-silane $\left(\mathrm{Si}\left[\mathrm{OC}_{2} \mathrm{H}_{5}\right]_{4}\right.$, TEOS, molar mass: 208 $\mathrm{g} / \mathrm{mol}$, boiling point: $168^{\circ} \mathrm{C}$, FUJIFILM Wako Pure Chemical Corporation,), and octamethyl-cyclotetrasiloxane $\left(\left[\mathrm{CH}_{3}\right]_{2} \mathrm{OSi}\right)_{4}$, OMCTSO, molar mass: $297 \mathrm{~g} / \mathrm{mol}$, boiling point: $176^{\circ} \mathrm{C}$, Fujifilm Wako Pure Chemical Corporation) were used as the raw monomer. These monomers $(0.12-$ $0.13 \mathrm{~kg} / \mathrm{h})$ with air $\left(0.7 \mathrm{Nm}^{3} / \mathrm{h}\right)$ and $\mathrm{N}_{2}\left(0.02 \mathrm{Nm}^{3} / \mathrm{h}\right)$ were put into the flame $\left(\mathrm{H}_{2}: 0.2 \mathrm{Nm}^{3} / \mathrm{h}, \mathrm{O}_{2}: 0.15 \mathrm{Nm}^{3} / \mathrm{h}\right.$, and $\left.6 \mathrm{Nm}^{3} / \mathrm{h}\right)$ from the burner nozzle (inner diameter: $2 \mathrm{~mm}$ ). After firing in the flame, the formed silica was immediately air-cooled $\left(1.6 \mathrm{Nm}^{3} / \mathrm{h}\right)$.

\section{B. Characterization of Silica Particles}

Crystalline structures of the obtained silica particles were analyzed with $\mathrm{CuK} \alpha$ radiation using an X-ray diffractometer (Rigaku) fitted with a nickel filter. The morphologies of the sol particles and the obtained silica particles were analyzed using a field emission scanning electron microscope (Jeol, JSM-7800F) operating at $5 \mathrm{kV}$. The particle size distribution was determined with a laser particle-size analyzer (Otsuka Electronics, LPA-3000, 3100).

\section{RESULT AND DISCUSSION}

\section{A. Spherical Silica Particles Synthesized by Wet Processes}

Several types of wet processes have been developed for obtaining spherical silica particles. In this study, firstly, an alkoxy process using MTMS was adopted. As mentioned earlier, a solution- 1 containing $1.8 \mathrm{ml}$ of MTMS and $20 \mathrm{ml}$ of ethanol was magnetically stirred and cooled $\left(0-5^{\circ} \mathrm{C}\right)$ by using a handmade heat exchanger. A solution-2 containing $5.5 \mathrm{ml}$ of ammonium hydroxide in $8 \mathrm{ml}$ of distilled water was cooled to the same temperature as the previous solution-1. The synthesis reaction was performed by dropping the solution-2 into the solution-1 slowly. In the first step, a hydrolysis reaction occurs with a nucleophilic attack of the oxygen of water $\left(\mathrm{H}_{2} \mathrm{O}\right)$ on the silicon atom of the MTMS to form a hydroxy silane; subsequently, a condensation reaction between the $\equiv \mathrm{Si}-\mathrm{OH}$ groups occurs to produce a siloxane structure composed of $\left(-\mathrm{Si}\left(\mathrm{CH}_{3}\right)(\mathrm{O}-)-\mathrm{O}-\right) \mathrm{n}$. This is because the electronegativity of silicon (1.90) is much lower than that of carbon (2.55) and oxygen (3.44). Thus, the silicon atom of MTMS is easily attacked by the lone pair of electrons of oxygen to produce the siloxane structure. The reaction scheme is shown in Fig. 2. The abovementioned condensation reaction resulted in slow propagation of the siloxane polymer (precursor-polymer) particle.

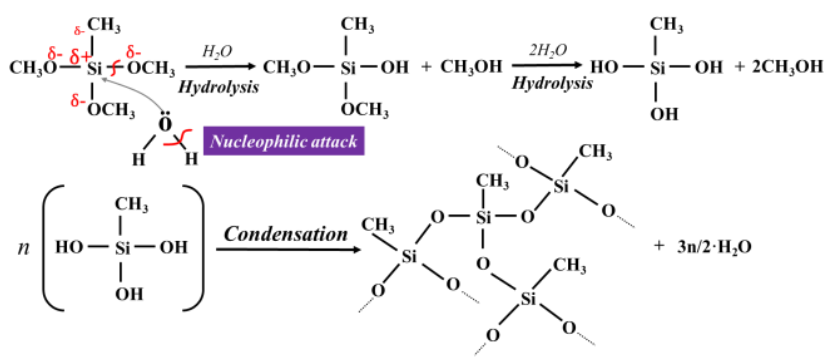

Electronegativity: $\mathrm{Si}(1.90)<C(2.55)<<O(3.44)$

Fig. 2. Hydrolysis reaction of MTMA and a condensation reaction between the formed $\equiv \mathrm{Si}-\mathrm{OH}$ groups.

The change in particle size of the precursor-polymer is shown in Fig. 3.

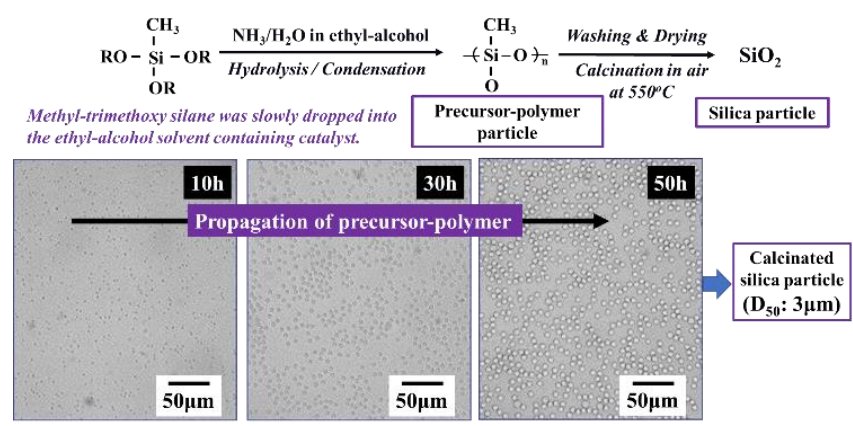

Fig. 3. Change in particle size of the precursor-polymer during the condensation reaction.

Remarkable growth of the particle size can be observed during the condensation reaction carried out for $50 \mathrm{~h}$. This result shows that although the obtained particle size can be easily controlled by changing the reaction time, a relatively long time is needed to produce larger particle sizes. As can be seen from Fig. 2, because the obtained precursor-polymer particle contained methyl groups, the precursor-polymer particle was calcinated at $550{ }^{\circ} \mathrm{C}$ in air to obtain silica particles $\left(\mathrm{D}_{50}: 3 \mu \mathrm{m}\right)$. The X-ray diffraction pattern of the obtained silica particles showed the structure of amorphous silica (Fig. 4).

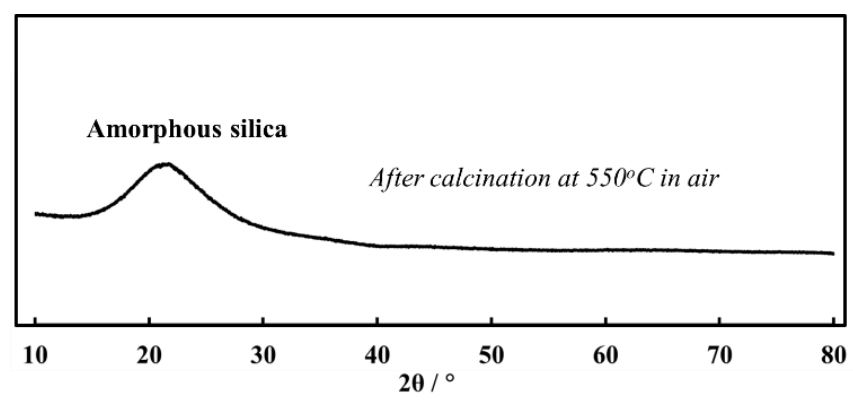

Fig. 4. X-ray diffraction pattern of the silica particles obtained by the wet process using MTMS.

As mentioned earlier, as the condensation reaction of MTMS needs a relatively long time, to synthesize lager silica particles a new process was proposed (Fig. 5). In this process, silica seed particles $(8 \mu \mathrm{m})$ were first added to ethyl alcohol containing $\mathrm{NH}_{3} / \mathrm{H}_{2} \mathrm{O}$ catalyst. Next, the aforementioned solution-1 was slowly dropped into the ethyl alcohol solution. Silica exhibits very high wettability because the critical 
surface tension of silica is very large $(200-400 \mathrm{mN} / \mathrm{m})$. This is caused by the existence of -OH groups on the surface of silica. That is, during the reaction, it is supposed that the newly dropped MTMS reacts with the $-\mathrm{OH}$ groups and the propagation proceeds by this condensation reaction. Using this process, very large spherical silica particles $\left(D_{50}: 20 \mu \mathrm{m}\right)$ were synthesized (Fig. 5).

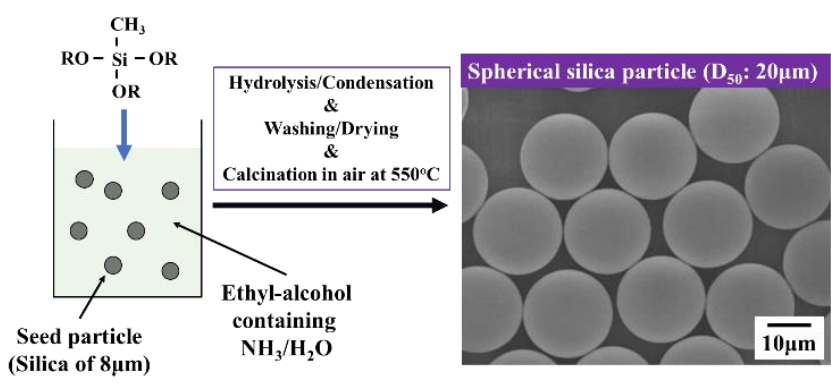

Critical surface tension of silica: $200 \sim 400 \mathrm{mN} / \mathrm{m} \leftarrow$ Very high wettability

Fig. 5. A new process to synthesize larger silica particles.

Thus, although the wet process needs a relatively long reaction time, it is a very useful method for synthesizing spherical silica particles with a wide range of particle size.

\section{B. Spherical Silica Particles Synthesized by Dry Processes}

The dry process using flame has been used to produce various silica particles of ceramic and composite materials, ranging in size from a few to several hundred nanometers. This method can produce high-purity particles continuously without further treatments such as drying, calcination, and milling. Thus, the dry process is advantageous for industrial mass production. As mentioned earlier, in this study, we used three types of monomers (MTMS, TEOS, and OMCTSO) with relatively low boiling points of less than $200^{\circ} \mathrm{C}$. These monomers $(0.12-0.13 \mathrm{~kg} / \mathrm{h})$ together with air $\left(0.7 \mathrm{Nm}^{3} / \mathrm{h}\right)$ and $\mathrm{N}_{2}\left(0.02 \mathrm{Nm}^{3} / \mathrm{h}\right)$ were put into the flame $\left(\mathrm{H}_{2}: 0.2 \mathrm{Nm}^{3} / \mathrm{h}, \mathrm{O}_{2}\right.$ : $0.15 \mathrm{Nm}^{3} / \mathrm{h}$, and $6 \mathrm{Nm}^{3} / \mathrm{h}$ ) from the burner nozzle (inner diameter: $2 \mathrm{~mm}$ ). In the initial stage, near the burner nozzle, oxidative condensation reactions of these monomers with fed oxygen are thought to occur, forming condensed particles in a very short time. These condensation reactions are dominated by the molecular structures of the monomers. The molecular structure and physical properties of the monomers used are shown in Table I.

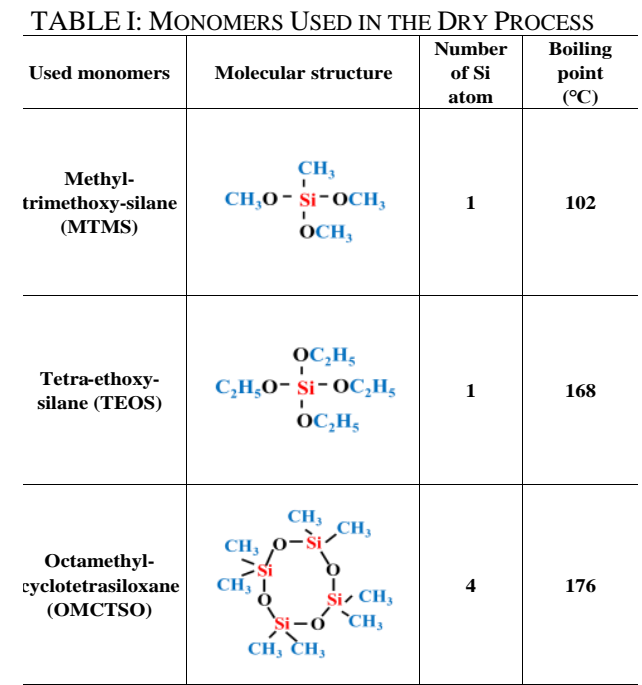

It can be seen from this table that although the number of $\mathrm{Si}$ atoms of MTMS and TEOS is the same (one), the substituent groups of these monomers are different from each other. The aforementioned condensation reaction is thought to be dominated by the bulkiness of the substituent group. On the other hand, OMCTSO has four silicon atoms in the monomer; its calcination can lead to effective silica formation.

The schematic image of the dry process using $\mathrm{Si}$ containing monomers is shown in Figure 6. The monomers fed into frame are converted to silica particles via an oxidative condensation reaction, formation of fine silica particles, coalescence, and propagation in the frame. In this case, the size of the obtained silica particles is determined by the molecular structure of the monomer. In the oxidative condensation reaction, the $\equiv \mathrm{Si}-\mathrm{R}$ groups are attacked by fed oxygen along with hydrogen to form $\equiv \mathrm{Si}-\mathrm{OH}$ groups; subsequently, the dehydration condensation reaction occurs to form condensed particles (precursor materials) before formation of fine silica particles by firing. The mechanism of the above reactions has been studied in detail [9]. During the conversion process from the Si-containing monomer to the silica particle, the precursor material formed by the oxidative condensation reaction greatly affects the size of the obtained silica particles; in particular, the size is dominated by the number of silicon atom contained in the monomer and the bulkiness of the substituent group.

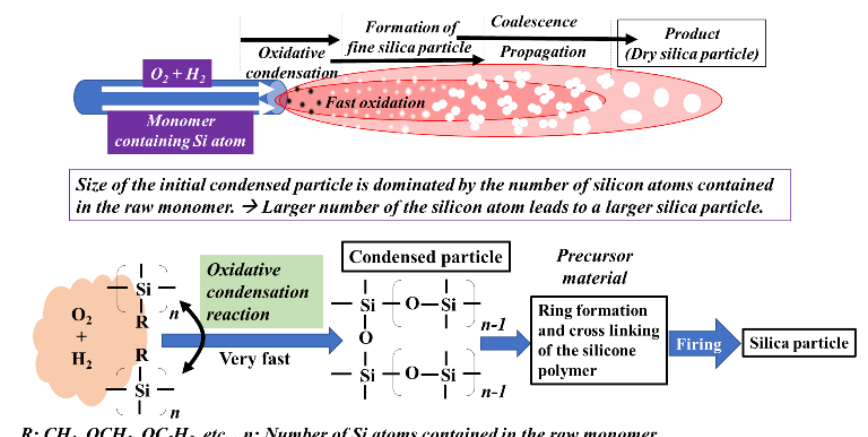

Fig. 6. Schematic image of the dry process using Si-containing monomers.

The FE-SEM image of the obtained silica particles synthesized from different monomers is shown in Fig. 7. The largest silica particle $\left(\mathrm{D}_{50}: 105 \mathrm{~nm}\right)$ was synthesized from OMCTSO, which contains the largest number of silicon atoms. TEOS, whose substituent group is relatively bulky, produced the smaller silica particles $\left(\mathrm{D}_{50}: 65 \mathrm{~nm}\right.$ ) than those $\left(\mathrm{D}_{50}: 85 \mathrm{~nm}\right)$ synthesized from MTMS.

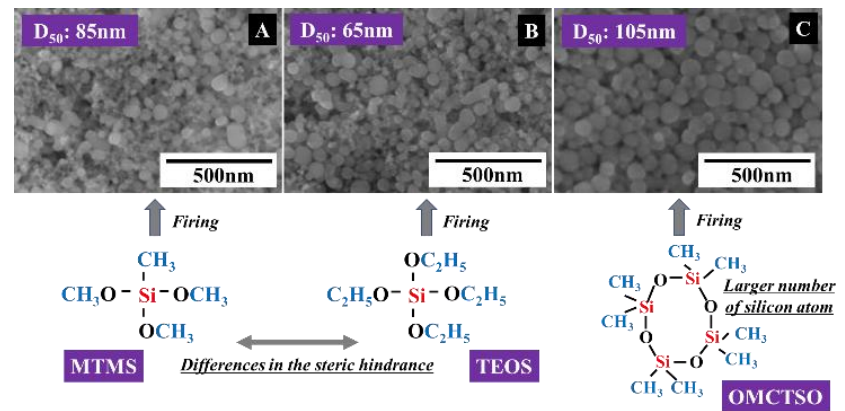

Fig. 7. FE-SEM image of the obtained silica particles synthesized from different monomers. 


\section{Controlling Factors of the Size of the Silica Particles}

In this paper, we described important controlling factors of the size of the silica particles synthesized by different processes (wet process and dry process) using several types of starting materials. Although the wet process needs a relatively long reaction time, a wide range of particle size and a narrow size distribution can be obtained. Furthermore, by using additional silica seed particles, larger silica particles can be synthesized. On the other hand, relatively fine silica particles can be synthesized via dry process in a very short time. In the dry process, the particle size is dominated by the structure of the fed monomer: in particular, the number of silicon atoms contained in the monomer and the bulky substituent group of the monomer. Because the dry process can produce high-purity particles continuously without further treatments such as drying, calcination, and milling, it is suitable for industrial mass production. Figure 8 shows the differences between the controlling factors of the particle size for the wet and dry processes.

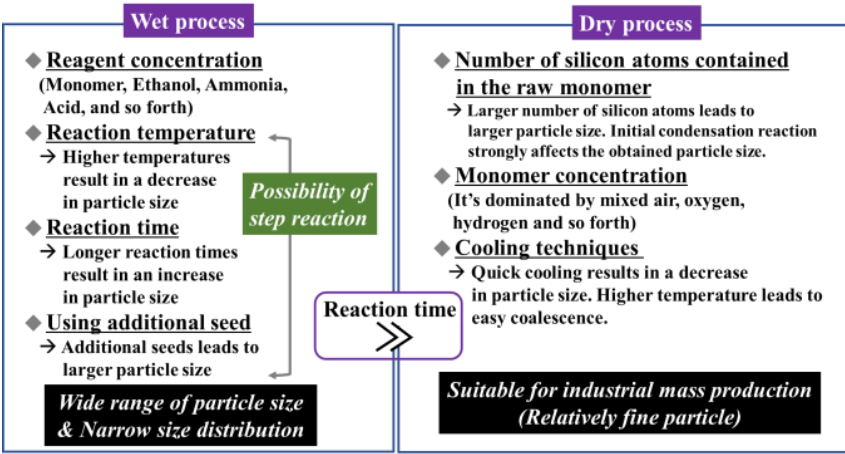

Fig. 8. Differences between the controlling factors of the particle size for the wet and dry processes.

\section{CONCLUSION}

We synthesized several types of silica particles via two types of processes (wet process and dry process). In the wet process, we used a sol-gel process with MTMS as a starting monomer. In this process, remarkable growth of the particle size of the condensed siloxane polymer was observed. To synthesize larger silica particles, a relatively long time was needed. However, the obtained particle size can be easily controlled by changing the reaction time. Further, using additional silica seed particles, larger silica particles were synthesized. On the other hand, in the dry process, we synthesized silica particles from three types of monomers (MTMS, TEOS, and OMCTSO). The size of the obtained silica particles was dominated by the molecular structure of the monomer: in particular, the number of silicon atoms contained in the monomer and the bulkiness of the substituent group. The largest silica particles were synthesized from OMCTSO, which contains the largest number of silicon atoms.

\section{REFERENCES}

[1] H. Kamiya, M. Mitsui, H. Takano, S. Miyazawa. Influence of particle diameter on surface silanol structure, hydration force, and aggregation behavior of alkoxide-derived silica particles. J. Am. Ceram. Soc., 2000;83(2): 287-293.
[2] K. D. Kim, H. T. Kim. New process for the preparation of monodispersed, spherical silica particles. J. Am. Ceram. Soc., 2002;85(5):1107-1113

[3] Y. Ji, H. Y. Sohn, H. D. Jang, B. Wan, T. A. Ring. Computational fluid dynamic modeling of a flame reaction process for silica nanopowder synthesis from tetraethylorthosilicate. J. Am. Ceram. Soc., 2007;90(12):3838-3845.

[4] M. Aoki, Y. Chikashige, T. Komatsubara, M. Ueda. Surface structure of fumed silica. The Imaging Society of Japan, 2015;54(2):140-147.

[5] T. G. Kim, G. S. An, J. S. Han, J. U. Hur, B. G. Park, S. C. Choi Synthesis of size controlled spherical silica nanoparticles via sol-gel process within hydrophilic solvent. Journal of the Korean Ceramic Society, 2017;54(1):49-54.

[6] A. Gurav, T. Kodas, T. Pluym, Y. Xiong Y. Aerosol processing of materials. Aerosol Sci. Technol., 1993;19: 411-452.

[7] H. K. Kammler, L. Madler, S. E. Pratsinis. Flame synthesis of nanoparticles. Chem. Eng. Technol., 2001;24:583-596.

[8] T. Adachi. Silica microparticles used for LCD spacer. Journal of the Surface Finishing Society of Japan, 2006;57(6):396-400.

[9] W. Zhu, S. E. Pratsinis. Synthesis of $\mathrm{SiO}_{2}$ and $\mathrm{SnO}_{2}$ particles in diffusion flame reactions. A. I. Ch. E. J., 1997;43:2657-2664.

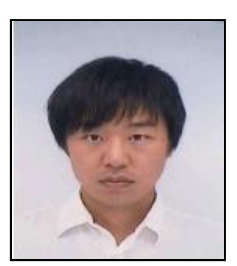

Keiji Saiki obtained M.Eng. degree from Okayama University, Japan. He is Assistant Manager of Silica \& Derivatives Development Department of Tokuyama Corporation in Japan. $\mathrm{He}$ has developed many kinds of inorganic powders and their new processes. Now, he is learning in Tokyo University of Science, Yamaguchi (Sanyo-Onoda City University) for receiving $\mathrm{Ph}$. D degree.

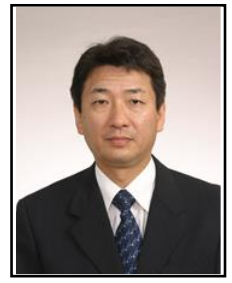

Toshihiro Ishikawa is Professor of Tokyo University of Science, Yamaguchi (Sanyo-Onoda City University). He received Ph.D degree from Osaka Prefecture University. He was engaged in the development of new functional ceramics and has authored or co-authored more than 150 peerreviewed papers (including two "Nature" papers and one "Science" paper). He has received lots of awards and prizes including Bridge Building Award (2020), GSC Award (2004), Award from the Minister for Environment (2004), Yamazaki Teiichi Prize, Japan (2003), Award from the Society of Chemical Engineers, Japan (2003), and Award from the Society of Polymer Science, Japan (1992). Now, he is also Fellow of American Ceramic Society, and Academician of World Academy of Ceramics. 